\title{
Within-class differences of the sulfonylureas should be accounted for
}

\author{
Dennis Schrijnders • Nanne Kleefstra • \\ Gijs W. D. Landman
}

Received: 11 February 2015 / Accepted: 12 February 2015 / Published online: 24 March 2015

(C) Springer-Verlag Berlin Heidelberg 2015

Keywords Cardiovascular events · Glibenclamide . Gliclazide · Hypoglycaemia · Sulfonylureas · Within-class differences

In a recent issue of Diabetologia, Riefflin et al published the results of their investigation into the effects of glibenclamide (known as glyburide in the USA and Canada) on insulin secretion in patients at different levels of glucose control [1]. We acknowledge that these results provide further evidence for the unique side-effect profile of glibenclamide. Unfortunately, in the discussion section, the results were repeatedly extrapolated to sulfonylureas as a class. For example, the final conclusion ends with 'This emphasises the need for cautious titration when using sulfonylureas as second-line agents after metformin when attempting to maintain tight glucose control.' The results of this study are largely confirmatory, given the overwhelming existing evidence that glibenclamide is associated with a higher risk of hypoglycaemia [2]. This extrapolation completely ignores important and clinically relevant withinclass differences among sulfonylureas. It is well known that of all the sulfonylureas, glibenclamide in particular is associat-

D. Schrijnders $(\triangle) \cdot$ N. Kleefstra $\cdot$ G. W. D. Landman

Diabetes Centre, Isala Clinics, Dokter Spanjaardweg 11,

8025 BT Zwolle, the Netherlands

e-mail: d.schrijnders@isala.nl

\section{N. Kleefstra}

Langerhans Medical Research Group, Zwolle, the Netherlands

\section{N. Kleefstra}

Department of Internal Medicine, University Medical Centre

Groningen, Groningen, the Netherlands

G. W. D. Landman

Department of Internal Medicine, Isala Clinics,

Zwolle, the Netherlands ed with a high rate of side effects, for example, more severe hypoglycaemic events and an increased number of cardiovascular events [2].

There are many reports that patients using glibenclamide are at an increased risk of mortality, and in a recent large, observational cohort study monotherapy with glibenclamide was associated with a higher mortality and cardiovascular risks, while gliclazide was associated with a risk comparable to that of metformin [3]. In the Netherlands, these within-class differences are even incorporated in the guidelines [4]; here, gliclazide is the preferred second treatment option after metformin. One of the other main advantages of gliclazide is its safety in severe renal failure [5]. In addition, two metaanalyses have reported that of all the sulfonylureas, gliclazide is associated with the lowest risk of hypoglycaemia [6]. For example, the hypoglycaemic event rate for gliclazide is $50 \%$ lower than that for glimepiride [7] and is comparable to that for dipeptidyl peptidase-4 inhibitors $[8,9]$.

In summary, in our opinion, Riefflin et al [1] should not have discussed their findings as applying to the sulfonylureas as a class, and we urge investigators and editors to bear in mind within-class differences.

Duality of interest The authors declare that there is no duality of interest associated with this manuscript.

Contribution statement All authors were responsible for drafting the article and revising it critically for important intellectual content. All authors approved the version to be published.

\section{References}

1. Riefflin A, Ayyagari U, Manley SE, Holman RR, Levy JC (2015) The effect of glibenclamide on insulin secretion at normal glucose concentrations. Diabetologia 58:43-49 
2. Gangji AS, Cukierman T, Gerstein HC, Goldsmith $\mathrm{CH}$, Clase CM (2007) A systematic review and meta-analysis of hypoglycemia and cardiovascular events: a comparison of glyburide with other secretagogues and with insulin. Diabetes Care 30:389-394

3. Schramm TK, Gislason GH, Vaag A et al (2011) Mortality and cardiovascular risk associated with different insulin secretagogues compared with metformin in type 2 diabetes, with or without a previous myocardial infarction: a nationwide study. Eur Heart J 32:1900-1908

4. Rutten GEHM, De Grauw WJC, Nijpels G et al (2013) NHGStandaard Diabetes mellitus type 2 (derde herziening). Huisarts Wet 56:512-525 (article in Dutch)

5. National Kidney Foundation (2012) KDOQI Clinical Practice Guideline for Diabetes and CKD: 2012 Update. Am J Kidney Dis 60:850-886
6. Landman GW, de Bock GH, van Hateren KJ et al (2014) Safety and efficacy of gliclazide as treatment for type 2 diabetes: a systematic review and meta-analysis of randomized trials. PLoS One 9:e82880

7. Schernthaner G, Grimaldi A, Di Mario U et al (2004) GUIDE study: double-blind comparison of once-daily gliclazide MR and glimepiride in type 2 diabetic patients. Eur J Clin Investig 34:535-542

8. Filozof C, Gautier JF (2010) A comparison of efficacy and safety of vildagliptin and gliclazide in combination with metformin in patients with Type 2 diabetes inadequately controlled with metformin alone: a 52-week, randomized study. Diabet Med 27:318-326

9. Foley JE, Sreenan S (2009) Efficacy and safety comparison between the DPP-4 inhibitor vildagliptin and the sulfonylurea gliclazide after two years of monotherapy in drug-naive patients with type 2 diabetes. Horm Metab Res 41:905-909 